\title{
Age and Growth of Japanese Mackerel in the High Seas of the Northwest Pacific Ocean
}

\author{
Heng Zhang1,2, Chao Yang, ${ }^{1,2}$, Bo Xu1,2,3,4*, Yongchuang Shi1,2, Guoqing Zhao, ${ }^{1,2}$, Haibin Han ${ }^{1,2}$ \\ ${ }^{1}$ East China Sea Fisheries Research Institute, China Academy of Fisheries Science, Key Laboratory of Innovation in Oceanic and \\ Polar Fisheries, Ministry of Agriculture and Rural Affairs, Shanghai, China \\ ${ }^{2}$ School of Oceanography, Shanghai Ocean University, Shanghai, China \\ ${ }^{3}$ Shanghai Zhiyuxiang Information Technology Co., Shanghai, China \\ ${ }^{4}$ Polar Research Institute of China, Shanghai, China \\ Email: *xubo6887@163.com
}

How to cite this paper: Zhang, H., Yang, C., Xu, B., Shi, Y.C., Zhao, G.Q. and Han, H.B. (2022) Age and Growth of Japanese Mackerel in the High Seas of the Northwest Pacific Ocean. Open Journal of Animal Sciences, 12, 91-102.

https://doi.org/10.4236/ojas.2022.121007

Received: November 14, 2021

Accepted: December 25, 2021

Published: December 28, 2021

Copyright (c) 2022 by author(s) and Scientific Research Publishing Inc. This work is licensed under the Creative Commons Attribution-NonCommercial International License (CC BY-NC 4.0).

http://creativecommons.org/licenses/by-nc/4.0/

\begin{abstract}
Japanese mackerel (Scomber japonicus) is one of the important economic species in the pelagic light seine fishery in China, but few studies have been reported on the age, growth and management recommendations of Japanese mackerel in the high seas of the northwest Pacific Ocean. In this study, we fitted expressions for the relationship between fork length and body weight of Japanese mackerel based on fork length and body weight data of Japanese mackerel in the high seas of the Northwest Pacific Ocean from 2018 to 2019, and calculated growth parameters and growth characteristics of Japanese mackerel von Bertalanffy growth equation by identifying otolith age data combined with the least squares method. The results showed that the relationship between fork length and body weight of Japanese mackerel in the open sea of the Northwest Pacific Ocean was $\mathrm{W}=2.0 \times 10^{-6} \mathrm{~L}^{3.289}(\mathrm{r}=0.9764$, $\mathrm{n}=2833$ ); the growth parameters were $\mathrm{L}=447.61_{\infty}, \mathrm{K}=0.264, \mathrm{t}=-1.06_{0}$; the growth rate reached the maximum when the bodyweight growth rate was 122 $\mathrm{g} / \mathrm{yr}$, at which the inflection point age was 3 years old, the inflection point body weight was $310 \mathrm{~g}$, and the inflection point length was $309 \mathrm{~mm}$. We recommend 2 years of age start fishing with a fork length of $250 \mathrm{~mm}( \pm 10$ $\mathrm{mm})$. The growth parameters of Japanese mackerel in the open sea of the Northwest Pacific Ocean were not significantly different from those of the Japanese mackerel population on Japan's coast $(P>0.05)$, Finally, based on the knowledge of biological research and resource evaluation, we suggest that the age of opening trap should be 2 years old and the length of fork should be $250 \mathrm{~mm}( \pm 10 \mathrm{~mm})$.
\end{abstract}

\section{Keywords}

Northwest Pacific High Seas, Japanese Mackerel, Growth Parameters, 
Fisheries Management

\section{Introduction}

Japanese mackerel (Scomber japonicus) is an oceanic warm-water pelagic fish, one of the important economic species of China's pelagic light seine fishery, mainly living in the northwest Pacific Ocean, divided into the Pacific group system and the Tsushima group system [1] [2] [3]. With Japanese mackerel being the main species caught, accounting for $50.2 \%$ of the total catch [4]. According to the statistics of The North Pacific Fisheries Commission (NPFC), the total catch of Japanese mackerel in the western Northwest Pacific Ocean from 2017 to 2019 showed a slightly decreasing trend for three consecutive years, and the reasons for the decree sing catch are still unclear, Japanese mackerel is the main species caught in the light seine in the North Pacific Ocean, and NPFC is very concerned about its resources. The research in this paper can provide basic data for NPFC's management of its resources [5]. The study of individual growth patterns of fish is the basis for studying the changes in the number of resource groups and their rational use, and growth increases the total amount of resources, which is one of the main factors affecting the number of resource groups. There have been many studies in the literature on the quantity, distribution and biology of Japanese mackerel in the offshore waters of China and Japan [6]-[15]. The only reports on Japanese mackerel in the high seas of the Northwest Pacific Ocean are Zhuang Zhidong et al. [16]. who studied the feeding habits, gonad maturity and fork length-body weight relationships of Japanese mackerel in the high seas of the Northwest Pacific Ocean in autumn; Dai [4] and Xu [5] who studied the distribution of Japanese mackerel in the high seas of the Northwest Pacific Ocean and the environmental characteristics of the fishing grounds; and a few studies who studied the environmental factors affecting the resources and parental replenishment of Japanese mackerel in the Pacific group [1] [17] [18]. In general, studies on the biology of Japanese mackerel fisheries in the high seas of the Northwest Pacific are rare [19] [20]. It is known that only a few scholars have partially studied the age and growth of Japanese mackerel Japan's coast [11] [12], and few studies have been reported on the age, growth and management recommendations of Japanese mackerel in the high seas of the Northwest Pacific Ocean.

Since the Japanese mackerel fishery is of great relevance to the expansion of China's high seas fishery and the improvement of the capacity building of the high seas fishery stock assessment system, and the strengthening of the research on the biological characteristics and stock growth of this fishery stock can provide the preliminary basic data for China's active participation in the assessment of mackerel resources in the Northwest Pacific Fisheries Commission. In this paper, the age determination and growth characteristics of Japanese mackerel in 
the high seas of the Northwest Pacific Ocean from 2018 to 2019 were analyzed to provide a reference basis for resource assessment and fisheries management.

\section{Materials and Methods}

\subsection{Material Sources}

Japanese mackerel in the high seas of the Northwest Pacific Ocean, randomly collected by fishing vessels, were studied in the sampling area of $39-44^{\circ} \mathrm{N}, 147$ $154^{\circ} \mathrm{E}$, and the sampling period was from April to December (fishing season) in 2018 and 2019. Samples were taken four times a month, 100 tails were taken each time, if the number of tails was less than 100 , and all samples were taken totaling 2833 tails (Frozen and shipped back to the lab via transport ship). The fishing date, latitude and longitude of each sampling location were recorded, and the samples were numbered and registered. The sampling area is shown in Figure 1.

\subsection{Fork Length-Weight Relationship}

Body length, fork length and full length of Japanese mackerel were measured by tape measure (accurate to $1 \mathrm{~mm}$ ); body weight was measured by electronic balance (accurate to $0.1 \mathrm{~g}$, Error range in $\pm 0.1 \mathrm{~g}$ ). The differences between fork length and body weight of Japanese mackerel by sex were examined by analysis of covariance (ANOVA), and then the fork length-weight growth relationship was fitted by power function [21] [22], as shown in Equation (1).

$$
W_{i}=a \times L_{i}^{b}
$$

$L_{i}$ denotes the mean fork length (mm) of the $i$ th fork length group, $W_{i}$ is the mean weight $(\mathrm{g})$ corresponding to $L_{\vec{p}} a$ is the condition factor for growth, and $b$ is the power index coefficient.

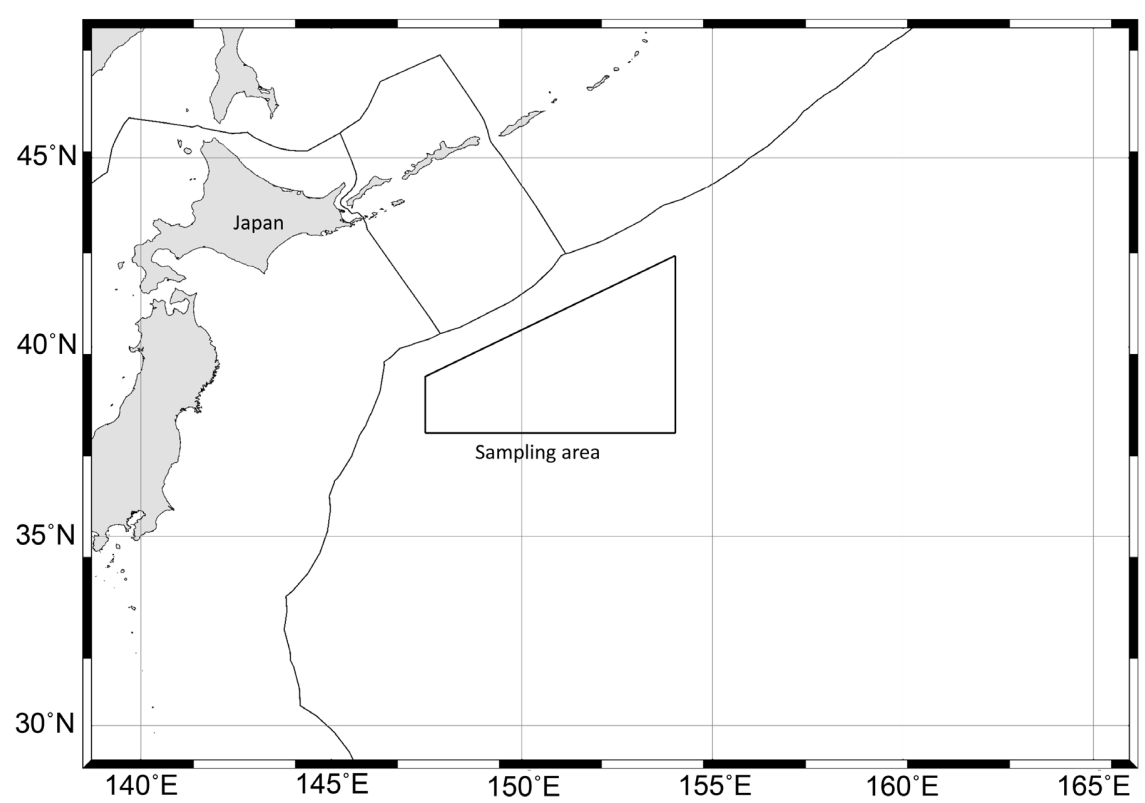

Figure 1. Schematic diagram of sampling location. 


\subsection{Age Identification}

During the life cycle of teleosts, the inner cavity of the skull is lined with carbonate deposits of "small stones" called otoliths. The main mineral component of otoliths is $\mathrm{CaCO}_{3}$, and fish rely on otoliths to distinguish sounds and maintain body balance [23]. Otoliths are used to identify the age of fish because the rate of $\mathrm{CaCO}_{3}$ deposition in otoliths varies with season, water temperature and physiological changes during the development of individual fish [24], resulting in a regular distribution of opaque zone and translucent zone around the core of otoliths, with one layer of transparent zone plus one layer of opaque zone being 1 age. In this paper, the cross-section of Japanese mackerel otoliths was used as a basis for age identification. The polished otoliths were photographed under a $100 \times$ light microscope (model: Olympus BX53), and the annual diameter and otolith diameter on the otolith photographs were measured by the measurement software Image J. The Dahl-Lee hypothesis was used to derive the fork length conversions for each age group of Japanese mackerel [25] [26]:

$$
\frac{L_{i}}{R_{i}}=\frac{L}{R}
$$

where $L_{i}$ is the back-calculated fork length $(\mathrm{mm})$ of the $i$ th age or annual whorl of Japanese mackerel; $L$ is the fork length $(\mathrm{mm})$ of that individual; $R_{i}$ is the $i$ th annual whorl diameter, which refers to the straight-line distance $(\mathrm{mm})$ from the core point of the otolith to the ith annual whorl of the otolith, and the whorl pattern is measured by the outer edge of the opaque band; $R$ is the otolith diameter, which refers to the straight-line distance $(\mathrm{mm})$ from the core point of the otolith to the outermost edge. The schematic diagram of otolith chronology measurement is shown in Figure 2.

To enhance the accuracy of age identification, the otoliths used for age reading should be relatively transparent in cross-section, with the whorls clearly visible, and as much as possible, the secondary whorls should be brought together in

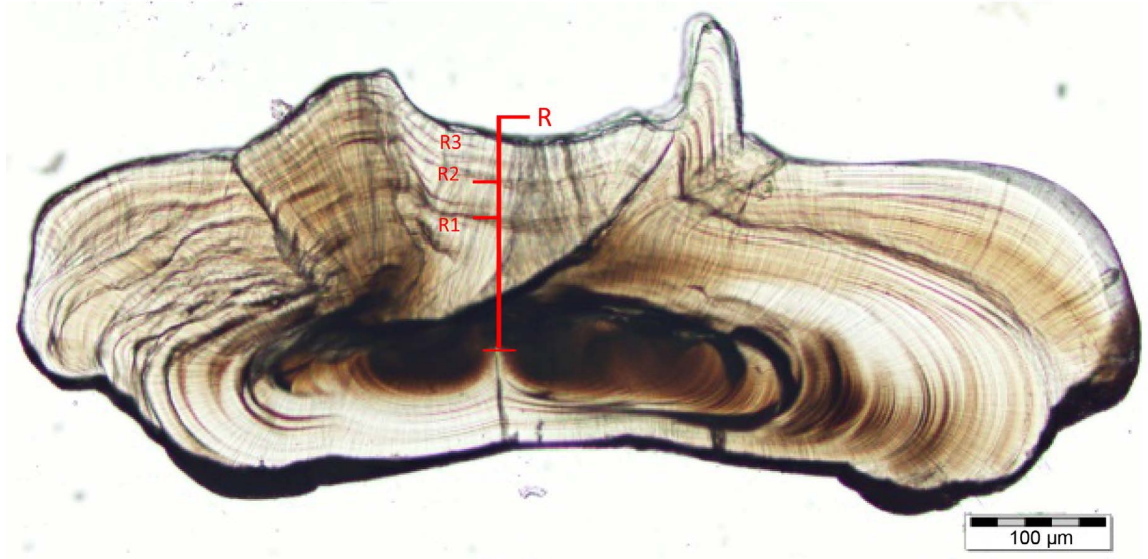

Figure 2. Schematic diagram of age determination of Japanese mackerel otoliths (fork length of this individual is $309 \mathrm{~mm}$, age $3^{+}$). 
one place during the polishing process to reduce the interference with age identification. When measuring the diameter of the whorls on the photographs of the otoliths, the alternating zone between the transparent and opaque bands in transmitted light was used as the location of the annual whorls, and the diameter of all the secondary whorls, annual whorls and interfering whorls was recorded [26]. Each otolith age reading was performed independently of each other by two persons with solid otolith reading experience, and the age identification was considered reliable if the judgment was consistent or re-reading or discarding the sample if it was inconsistent.

\subsection{Growth Parameters}

In fisheries research, the von Bertalanffy growth equation can elucidate the age-dependent variation of length and weight of fish, and the growth process can be fitted with the data of minimum parameters. The equation is generally used to fit and describe the growth pattern of fish, and the least squares method is used to determine the optimal growth parameters for the von Bertalanffy growth equation [21] [27].

Fork length growth equation.

$$
L_{t}=L_{\infty} \times\left\{1-\mathrm{e}^{\left[-K \times\left(t-t_{0}\right)\right]}\right\}
$$

Weight growth equation.

$$
W_{t}=W_{\infty} \times\left\{1-\mathrm{e}^{\left[-K \times\left(t-t_{0}\right)\right]}\right\}
$$

$L_{t}$ and $W_{t}$ denote the fork length $(\mathrm{mm})$ and weight value $(\mathrm{g})$ of Japanese mackerel at age $t, L_{\infty}$ and $W_{\infty}$ denote the ultimate fork length $(\mathrm{mm})$ and ultimate weight $(\mathrm{g})$ of Japanese mackerel; $t_{0}$ denotes the age when the theoretical fork length $\left(L_{t}\right)$ or weight $\left(W_{t}\right)$ is equal to zero, often a negative number; $K$ is the average curvature of the growth curve, indicating the relative rate of convergence to the asymptotic value.

\section{Results}

\subsection{Fork Length and Weight}

It was found that there was no significant difference in fork length and body weight between male and female Japanese mackerel individuals $(P>0.05)$. The relationship between fork length and body weight was expressed as $W=2.0 \times$ $10^{-6} L^{3.289}(r=0.9764, n=2833)$, where the growth condition factor a was $2 \times$ $10^{-6}$ and the power index coefficient b was 3.289 (Figure 3).

\subsection{Growth Equation}

\subsubsection{Age Identification and Fork Length-Age Conversion Table}

The total number of samples used for otolith age identification in 2018 and 2019 was 317 , including 5 at age $0^{+}, 92$ at age $1^{+}, 170$ at age $2^{+}, 44$ at age $3^{+}$, and 6 at age $4^{+}$. Fork lengths and age back-calculations were performed according to the 


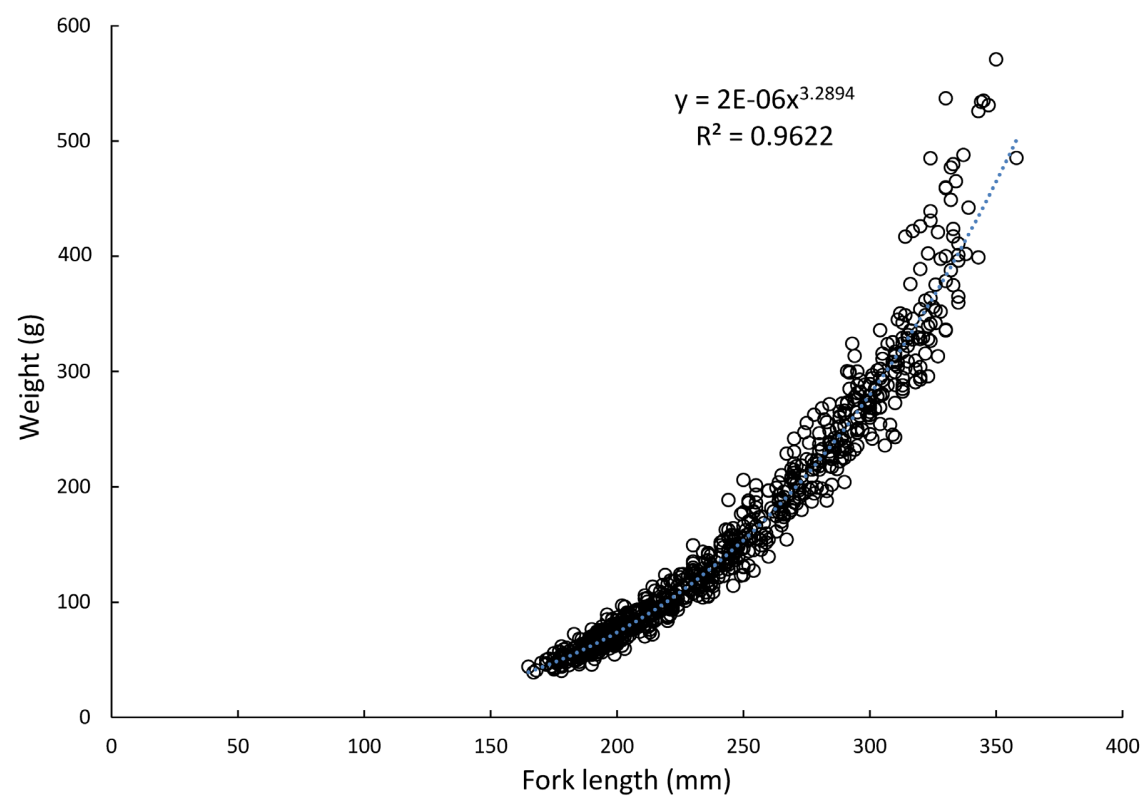

Figure 3. Relationship between fork length and body weight of Japanese mackerel in the Northwest Pacific.

otolith wheel diameter, and the corresponding average back-calculated fork lengths for each age were $187.83 \mathrm{~mm}$ at age $1^{+}, 248.38 \mathrm{~mm}$ at age $2^{+}, 294.01 \mathrm{~mm}$ at age $3^{+}$, and $318.46 \mathrm{~mm}$ at age $4^{+}$, as shown in Table 1 .

\subsubsection{Growth Parameter Estimation}

Based on the age and corresponding fork length data listed in Table 1, the growth parameters of Japanese mackerel were obtained as $L_{\infty}=447.61 \mathrm{~mm}, K=$ 0.264 , and $t_{0}=-1.06$, respectively, using the least squares method to estimate the von Bertalanffy growth equation.

\subsection{Growth Rate and Growth Inflection Point}

The weight growth equation is:

$$
W_{t}=1046.74 \times\left\{1-\mathrm{e}^{[-0.264 \times(t+1.06)]}\right\}^{3.289}
$$

The weight growth rate of Japanese mackerel with age as well as weight change curve can be plotted from the weight growth equation (Figure 4). From Figure 4(a), it can be seen that during the period from 0 to 8 years of age, the body weight growth rate was the smallest at age 0 , at $37.33 \mathrm{~g} / \mathrm{yr}$, but the bodyweight growth acceleration (slope of the curve $\mathrm{d}^{2} \mathrm{Wt} / \mathrm{dt}^{2}$ ) was the largest at this time, and the Japanese mackerel grew the fastest. The body weight growth rate continued to increase from 0 to 3.1 years of age, which is the rapid growth period of Japanese mackerel, and the bodyweight growth acceleration was 0 at 3.1 years of age when the bodyweight growth rate reached the maximum value of $122 \mathrm{~g} / \mathrm{yr}$. Thereafter, the bodyweight growth rate gradually decreased from 3.1 to 8 years of age, indicating that the growth and development of Japanese mackerel entered a slow growth period. 


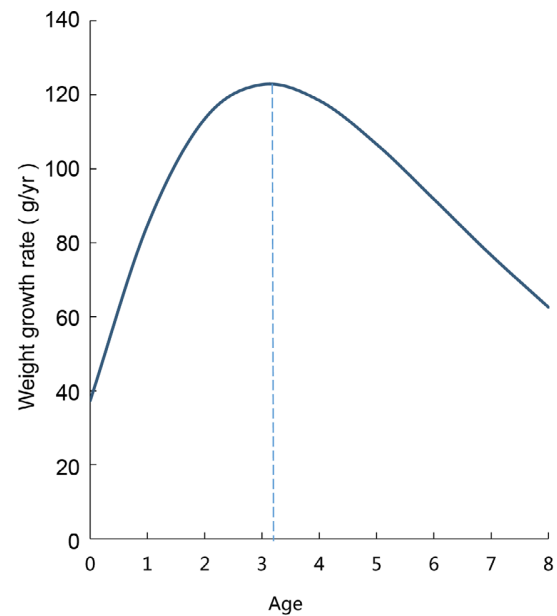

(a)

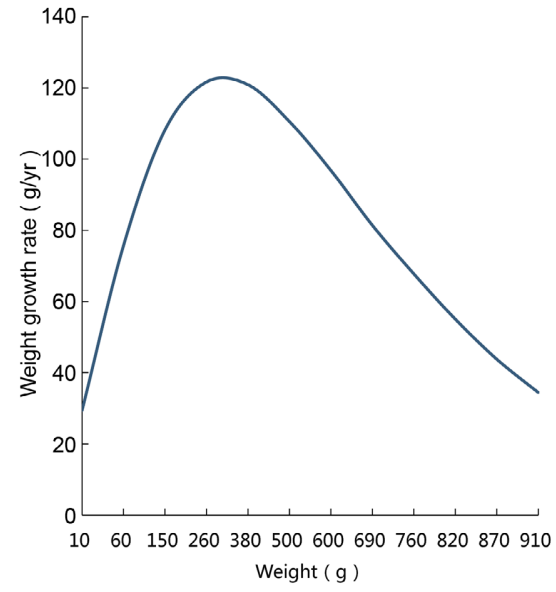

(b)

Figure 4. Bodyweight growth rate curve of Japanese mackerel ((a) is the bodyweight growth rate curve of Japanese mackerel with age; (b) is the bodyweight growth rate curve of Japanese mackerel with bodyweight).

Table 1. Back-calculated fork lengths corresponding to different ages of Japanese mackerel in the North Pacific high seas.

\begin{tabular}{ccccc}
\hline Age/Fork length & $L_{1}(\mathrm{~mm})$ & $L_{2}(\mathrm{~mm})$ & $L_{3}(\mathrm{~mm})$ & $L_{4}(\mathrm{~mm})$ \\
\hline 1 & 187.00 & & & \\
2 & 185.89 & 247.85 & & \\
3 & 192.64 & 251.81 & 302.72 & \\
4 & 185.77 & 245.48 & 285.29 & 318.46 \\
Average & 187.83 & 248.38 & 294.00 & 318.46 \\
\hline
\end{tabular}

As can be seen from Figure 4(b), the body weight growth rate also showed a trend of accelerating and then decelerating in the range of body weight change from 0 to $910 \mathrm{~g}$. When the bodyweight growth acceleration was $122 \mathrm{~g} / \mathrm{yr}$, the corresponding body weight was $310 \mathrm{~g}$. Then the bodyweight growth acceleration became negative and the bodyweight growth rate decreased gradually, and the Japanese mackerel body weight increased slowly. When the weight growth acceleration was $122 \mathrm{~g} / \mathrm{yr}$, the corresponding weight was $310 \mathrm{~g}$. Then the weight growth acceleration became negative, the weight growth rate gradually decreased, and the weight gain of Japanese mackerel became slower. Therefore, the inflection point weight of Japanese mackerel in this study was $310 \mathrm{~g}$, the inflection point age $t_{p}=3.1$ years, and the inflection point fork length $L_{p}=309 \mathrm{~mm}$.

\section{Discussion}

\subsection{Relationship between Fork Length and Body Weight}

The relationship between fork length and body weight of pelagic fishes has been shown to be a power function [21] [22] [23] [24] [25], and in this study, we also 
found a significant relationship between fork length and body weight of Japanese mackerel $\left(R^{2}=0.9764, n=2833\right)$. It is generally believed that the power index in the relationship between fork length and body weight can be used to determine whether the fish is growing at the same rate if the power index is $2.5<3<3.5$, it means that the fish is growing at the same rate, which means that the growth rate of the individual in the three directions of length, width and height is close to each other in the process of growing from small to large [21].

\subsection{Reliability of Otolith Age Identification}

Most pelagic fish age identification is based on otoliths, and the resin-embedded otolith molds are polished to a thickness of about $0.2 \mathrm{~mm}$ by a grinding and polishing machine, and the age is identified and the whorl diameter is measured under an optical microscope, based on this age identification method it is easier to determine the actual age composition of the fish [6] [25] [27], but there is sometimes some error in the accurate interpretation of the otoliths [28]. To enhance the accuracy of age determination, the otoliths used for age determination should be relatively transparent in cross-section and the whorls should be clearly visible, and as much as possible, the miscellaneous whorls should be brought together in one place during the polishing process to reduce the interference with age determination. When measuring the whorls on the otolith photographs, the alternating transparent and opaque bands in transmitted light were used as the location of the annual whorls, and the whorls of all the secondary whorls, annual whorls, and interfering whorls were recorded [29]. In this study, the average fork length values corresponding to the age back-calculation (with a margin of error of $\pm 2 \mathrm{~cm}$ ) were determined as the fork lengths corresponding to different ages of Japanese mackerel. All data were observed and recorded by two researchers with experience in age identification, and the age-fork length data recorded by the two researchers were compared, and the error range of $\pm 1 \mathrm{~cm}$ for each age corresponding to the fork length was considered as the same data, and the data table of age-fork length relationship was finally obtained.

To verify the accuracy of otolith age identification, the growth curves of Japanese mackerel in this study were compared with those of Japanese mackerel from the Pacific group studied previously using F-test [29]. The results showed that there was no significant difference between the growth curves derived from the otolith age identification and the equations of the production curves of Japanese mackerel from different seas (Table 2, Figure 5). Therefore, it can be seen that the age identification of the present study has high reliability.

\subsection{Growth Parameters}

Comparing the results of the present study with the results of the growth equation parameters of Japanese mackerel in Japan's coast (Table 3) derived by Kawashima, Tokuei and others, we found that the limiting fork length $L_{\infty}$ of Japanese mackerel in the North Pacific high seas was higher than the results of 


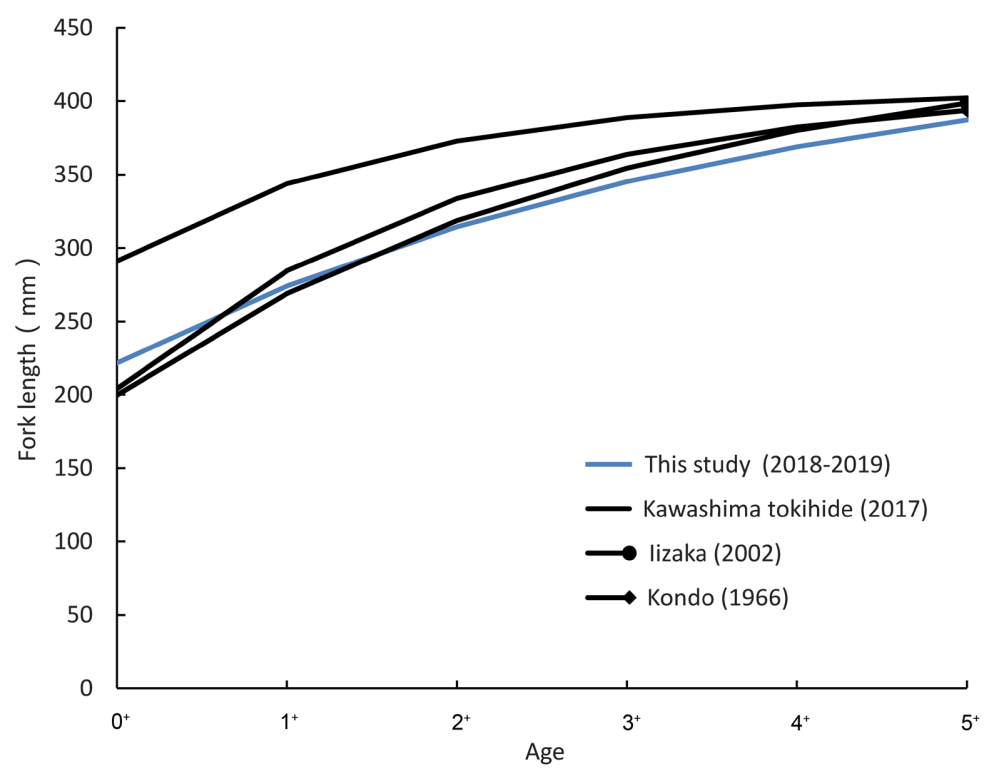

Figure 5. Comparison of the growth curves of the Japanese mackerel Pacific group.

Table 2. Significance analysis of the differences in growth curves among different samples of the Japanese mackerel Pacific group lineage.

\begin{tabular}{ccccccc}
\hline & \multicolumn{2}{c}{ Tokifusa } & \multicolumn{2}{c}{ Iizuki } & \multicolumn{2}{c}{ Keiichi } \\
& \multicolumn{2}{c}{$(2017)[29]$} & \multicolumn{2}{c}{$(2002)[30]$} & \multicolumn{2}{c}{$(1966)[31]$} \\
\hline F-test F-test & F-value & P-value & F-value & P-value & F-value & P-value \\
In this study & 1.254 & 0.395 & 0.626 & 0.292 & 0.528 & 0.228 \\
\hline
\end{tabular}

Table 3. Comparison of parameter estimates for the growth equation of Japanese mackerel von Bertalanffy.

\begin{tabular}{ccccc}
\hline \multirow{2}{*}{ Researchers } & Analysis Method & \multicolumn{3}{c}{ Parameter } \\
\cline { 3 - 5 } & & $L_{\infty}(\mathrm{mm})$ & $K$ & $t_{0}$ \\
\hline This study (2021) & Otoliths Otolith & 447.6 & 0.2641 & -1.59 \\
Tokifusa (2017) [29] & Otoliths Otolith & 408.1 & 0.6 & -1.082 \\
Iizuki (2002) [30] & Fish Scale Scale & 411.6 & 0.49 & -0.4 \\
Keiichi (1966) [31] & Fish Scale Scale & 446 & 0.33 & -0.8 \\
\hline
\end{tabular}

Tokifusa [29] and Iizuki [30], but similar to the results of Keiichi [31]. The $K$ and $t_{0}$ values in this study were small among all studies, which proved that the growth and development of Japanese mackerel in the North Pacific open sea were slower than those on Japan's coast.

\subsection{Growth Inflection Point of Japanese Mackerel}

The growth rate of fish reflects how fast or slow the fish increases in length or weight throughout its life. After understanding the growth rate of fish in each life stage, the period of fast growth to slow growth can be appropriately selected 
and utilized to maximize the fishery resources [21]. Wang Kai et al. analyzed the fishery resources of Japanese mackerel in the East China Sea according to the B-H (Beverton-Holt) dynamic integrated model, and suggested that the age at harvesting was 1.22 years old and the fork length at harvesting was $247 \mathrm{~mm}$ [7]; Liu Yong et al. studied that the inflection point age of Japanese mackerel in the north of the east China sea and the south of the yellow sea is 2.7 years, the inflection point weight is $450 \mathrm{~g}$, and the inflection point fork length is $320 \mathrm{~mm}$ [3]. In this study, the inflection point age of Japanese mackerel in the high seas of the Northwest It can be seen that there are some differences in the growth process of Japanese mackerel population in different sea areas and different ages, and the age of inflection point of Japanese mackerel tends to become larger with the increase of latitude. In fishery, the fishing standard can be formulated comprehensively with reference to a series of factors such as growth characteristics, natural mortality, fishing mortality, environmental factors, space-time conditions, utilization rate of dominant groups and economic benefits [3] [21]. Finally, combined with the data obtained in this paper, we recommend 2 years of age to be start fishing with a fork length of $250 \mathrm{~mm}( \pm 10 \mathrm{~mm})$. This suggestion will provide a biological reference for the follow-up resource assessment and fishery management of Japanese mackerel in the high seas of the Northwest Pacific.

\section{Acknowledgements}

This research was supported by National Key Research and Development Program of China (2019YFD0901405, 2018YFC1406802); Zhejiang ocean fishery resources exploration and capture project (CTZB-2021070657); Special Fund for Basic Scientific Research Business Expenses of the East China Sea Fisheries Research Institute of the Chinese Academy of Fisheries Sciences at the Central Level for Public Welfare (2021M06); Open Fund for the Ministry of Education/Shanghai Field Scientific Observation Research Station of the Yangtze Delta Estuarine Ecosystem (K202001); The project was completed with the support of the Open Fund of the Key Laboratory for Sustainable Development of Ocean Fishery Resources, Ministry of Education (A1-2006-00-301109). And we would not have been done without the help from many people.

\section{Grant}

National Key Research and Development Program of China (2019YFD0901405, 2018YFC1406802); Zhejiang Ocean Fishery Resources Exploration and Capture Project (CTZB-2021070657); Special Fund for Basic Scientific Research Business Expenses of the East China Sea Fisheries Research Institute of the Chinese Academy of Fisheries Sciences at the Central Level for Public Welfare (2021M06); Open Fund for the Ministry of Education/Shanghai Field Scientific Observation Research Station of the Yangtze Delta Estuarine Ecosystem (K202001).

\section{Conflicts of Interest}

The authors declare no conflicts of interest regarding the publication of this paper. 


\section{References}

[1] Lin, Q.Q., Chen, X.J. and Dai, L.B. (2018) Comparative Analysis of Stock-Recruitment Model for Scomber japonicus in the Pacific Based on Environment Factors. Marine Fisheries, 40, 279-286

[2] Cheng, J.H. and Lin, L.S. (2004) Sudy on the Biological Characteristics and Status of Common Mackerel (Scomber japonicus Houttuyn) Fishery in the East China Sea Region. Marine Fisheries, No. 2, 73-78.

[3] Liu, Y., Yan, L.P., Hu, F., et al. (2005) Age and Growth of Mackerel in the Northern East China Sea and Southern Yellow Sea. Marine Fisheries, No. 2, 133-138.

[4] Dai, S.W., Tang, F.H., Fan, W., et al. (2017) Distribution of Resource and Environment Characteristics of Fishing Ground of Scomber japonicas in the North Pacific high seas. Marine Fisheries, 39, 372-382.

[5] Xu, B., Zhang, H., Tang, F.H., et al. (2020) GAM-Based Analysis of the Relationship between Fishery Center of Gravity and Environmental Factors for Major Catch Species in High Seas Purse Seine in the North Pacific Ocean. Southern Fisheries Science, 16, 60-70.

[6] Yan, L.P., Zhang, H., Li, S.F., et al. (2012) Progress of Population Identification and Classification of Chub Mackerel (Scomber japonicus) in the East China Sea and the Yellow Sea. Marine Fisheries, 34, 217-221.

[7] Wang, K., Yan, L.P., Cheng, J.H., et al. (2007) Study on the Rational Utilization of Mackerel Resources in the East China Sea. Marine Fisheries, No. 4, 337-343.

[8] Li, G. and Chen, X.J. (2007) Tempo-Spatial Characteristic Analysis of the Mackerel Resource and Its Fishing Ground in the East China Sea. Periodical of Ocean University of China, 37, 921-926.

[9] Yuan, X.N., Chen, X.J. and Li, G. (2016) Annual Change of Fishing Ground Gravity for Scomber japonicas by Large Light Seine Fishery and Their Relationship with Environmental Factors in the East China Sea and Yellow Sea. Journal of Guangdong Ocean University, 36, 110-114.

[10] Li, J.S., Hu, F. and Yan, L.P. (2014) A Preliminary Study on Biological Characteristics of Chub Mackerel (Scomber japonicus) Spawning Stock in Central Taiwan Strait. Journal of Applied Oceanography, 33, 198-203.

[11] Murada, O., Yamamoto, S., Ishibashi, R., et al. (2005) Egg Development and Growth of Larval and Juvenile Cultured Chub Mackerel Scomber japonicus (Perciformes: Scombridae) in a Captive Spawning Experiment. Aquaculture Science, 53, 319-324.

[12] Wada, T., Sato, C. and Matsumiya, Y. (1996) Fisheries Management for the Pacific Stock of Chub Mackerel, Scomber japonicus, Based on Spawning Per Recruit Analysis. Fisheries Oceanography, 60, 363-371.

[13] Kamimura, Y., Takahashi, M., Yamashita, N., Watanabe, C. and Kawabata, A. (2015) Larval and Juvenile Growth of Chub Mackerel Scomber japonicus in Relation to Recruitment in the Western North Pacific. Fisheries Science, 81, 505-513. https://doi.org/10.1007/s12562-015-0869-4

[14] Kawai, H., Yatsu, A., Watanabe, C., Mitani, T., Katsukawa, T. and Matsuda, H. (2002) Recovery Policy for Chub Mackerel Stock Using Recruitment-per-Spawning. Fisheries Science, 68, 963-971. https://doi.org/10.1046/j.1444-2906.2002.00520.x

[15] Yoshiue, R., Watanabe, C., Uemura, T., et al. (2018) Stock Assessment of the Pacific Cohort of Chub Mackerel (Scomber japonicus) in 2018. National Research Institute of Fisheries Science, Japan, 3-11. 
[16] Zhuang, Z.D., Ma, C., Liu, Y., et al. (2018) A Preliminary Study on Biological Characteristics of Scomber japonicus in the North Pacific Ocean in Autumn. Transactions of Oceanology and Limnology, No. 6, 125-131.

[17] Wu, S.N., Chen, X.J. and Liu, Z.N. (2019) Establishment of Forecasting Model of the Abundance Index for Chub Mackerel (Scomber japonicus) in the Northwest Pacific Ocean Based on GAM. Acta Oceanologia Sinica, 41, 36-42.

[18] Wu, S.N. and Chen, X.J. (2020) Relationship between the Recruitment of the Pacific-Cohort of Chub Mackerel (Scomber japonicus) and the Influence Factors on the Spawning Ground Based on GLM and GAM. Journal of Fisheries of China, 44, 61-70.

[19] Cheng, J. (2013) Molecular Phylogeography of Two Scomber Species in Northwestern Pacific. Ocean University of China, Qingdao.

[20] Wu, S.N. and Chen, X.J. (2018) Review on Fishery Biology and Fishery Oceanography of Chub Mackerel (Scomber japonicus) in the Northwest Pacific Ocean. Journal of Guangdong Ocean University, 38, 91-100.

[21] Zhan, B.Y. (1993) Fish Stock Assessment. China Agriculture Press, Beijing, 18-44.

[22] Chen, D.G. (1997) Fisheries Stock Biology. China Agriculture Press, Beijing, 40-48.

[23] Zhuang, L.C. (2013) Comparative Morphology of the Sagittal otolith in Four Sebastes spp. from the Bohai Sea and the Yellow Sea. Ocean University of China, Qingdao.

[24] Zhang, Z.G. and Wang, W.M. (2001) A Review of Otolith Research in Fishes. Journal of Zhanjiang Ocean University, No. 4, 77-83.

[25] He, M.F., Li, X.H., Qin, X.C., et al. (2007) Age Determination and the Growth of Megalobrama hoffimanni in Xijiang River. Freshwater Fisheries, No. 3, 54-58.

[26] Hu, C.L., Zhang, Y.Z., Li, D.W., et al. (2018) Study on Fish Resources and Community Diversity During Spring and Summer in the Coastal Spawning Ground of Zhejiang Provience, China. Acta Hydrobiologica Sinica, 42, 984-995.

[27] Zhang, Y.Y., Chen, W.Y., Hu, Z.J., et al. (2020) Age and Growth of Crucian Carp Carassius auratus in Huangpu River and Dianshan Lake. Fisheries Science, 39, 787-795.

[28] Yan, Y.R., Hou, G., Lu, H.S. and Yin, Q.Q. (2011) Age and Growth of Pawak Croaker Pennahia pawak in Beibu Gulf. Journal of Fishery Sciences of China, 18, 145-155. https://doi.org/10.3724/SP.J.1118.2011.00145

[29] Tokifusa, K., Mitsuhiro, I. and Satoshi K. (2017) Age Determination of Chub Mackerel Scomber japonicus Using Otolith Transverse Section. Journal of Fisheries Technology, 9, 45-51.

[30] Iizuki, K. (2002) Mackerel Resources and Fishing Grounds in the 1960s and 1970s (Special Issue on Pacific Stock of Mackerel and Sesame Mackerel: Current Status and Future Prospects of Fisheries, Resources and Management). Marine, 34, 273-279.

[31] Keiichi, K. (1966) Growth of Mackerel Fishes-2-Age Assessment Method by Scales of Mackerel. Bulletin of Tokai Regional Fisheries Research Laboratory, 47, 31-49. 